\title{
Article \\ Effect of NACA0012 Airfoil Pitching Oscillation on Flow Past a Cylinder
}

\author{
Rong Han ${ }^{1, * \mathbb{D}}$, Wei Liu ${ }^{1}$, Xiao-Liang Yang ${ }^{1}$ and Xing-Hua Chang ${ }^{2}$ \\ 1 College of Aerospace Science and Engineering, National University of Defense Technology, \\ Changsha 410073, China; fishfather6525@sina.com (W.L.); yangxl_nudt@sina.com (X.-L.Y.) \\ 2 Unmanned Systems Research Center, National Innovation Institute of Defense Technology, \\ Beijing 100071, China; cxh_cardc@126.com \\ * Correspondence: hanrong@nudt.edu.cn; Tel.: +86-151-1613-3046
}

Citation: Han, R.; Liu, W.; Yang, X.-L.; Chang, X.-H. Effect of NACA0012 Airfoil Pitching Oscillation on Flow Past a Cylinder. Energies 2021, 14, 5582. https:// doi.org/10.3390/en14175582

Academic Editor: Ali Turan

Received: 28 July 2021

Accepted: 3 September 2021

Published: 6 September 2021

Publisher's Note: MDPI stays neutral with regard to jurisdictional claims in published maps and institutional affiliations.

Copyright: (c) 2021 by the authors. Licensee MDPI, Basel, Switzerland. This article is an open access article distributed under the terms and conditions of the Creative Commons Attribution (CC BY) license (https:// creativecommons.org/licenses/by/ $4.0 /)$.

\begin{abstract}
The flow past a cylinder is a classical problem in flow physics. In a certain range of Reynolds number, there will be Karman vortex street phenomenon in the wake of a cylinder, which will greatly increase the pressure drag of the cylinder. By controlling the vortex shedding phenomenon, drag reduction of the cylinder could be effectively realized. In this paper, a NACA0012 airfoil with pitching oscillation is placed downstream of the cylinder. Based on the tight coupling method, kinematics equations and Navier-Stokes equations in the arbitrary Lagrangian-Eulerian form are solved. Firstly, the effect of airfoil oscillation period and the distance between airfoil leading edge and cylinder center $(x / D)$ are studied respectively, especially considering the aspects of vortex shedding and drag reduction effect. Besides, the vortex interaction in the flow field around the airfoil and cylinder is analyzed in detail. It is found that the NACA0012 airfoil with pitching oscillation can change the period of vortex shedding. Moreover, it can also increase the drag reduction rate to as high as $50.5 \%$, which presents a certain application prospect in the engineering drag reduction field, e.g., for launch vehicles, ship masts, submarine pipelines, etc.
\end{abstract}

Keywords: flow past a circular cylinder; Karman vortex street; NACA0012 airfoil; pitching oscillation; drag reduction mechanism

\section{Introduction}

Flow past a cylinder is a common phenomenon of flow physics in nature and engineering practices, e.g., in launch vehicles [1,2], ship masts [3,4], submarine pipelines [5,6], and fluidics at the micro and nano scale [7,8]. Within the range of Reynolds number common in engineering practices, an alternately shedding Karman vortex street can be generated in the wake of a cylinder. The alternately shedding vortex creates a low-pressure area at the trailing edge of the cylinder, leading to a sharp increase in the pressure difference between the front and back walls of the cylinder. Pressure drag contributes most sources of resistance to the cylinder. On this basis, drag reduction can be effectively achieved in the cylinder via controlling the vortex shedding phenomenon.

Recently, achieving drag reduction through flow control has aroused extensive attention. Choi et al. [9] divided the control of flow past a cylinder into boundary layer control and wake adjustment. As mentioned in the literature [10], flow past a cylinder controlled using electromagnetic force can delay the separation of the turbulent boundary layer, thus decreasing resistance and suppressing lift pulsation. Jeon [11] and Kimura [12] made separation bubbles appear on the cylinder surface by means of blow-suction disturbance and adding cross grooves, so that drag reduction can be achieved with the separated-andreattaching flow of separation bubbles. Boundary layer control presents requirements regarding the object shape and Reynolds number. By comparison, it is simpler and more efficient to achieve drag reduction through controlling the cylindrical wake. 
By changing the flow state of the wake, the pressure distribution on the cylinder surface in the subsonic flow can be adjusted, thereby markedly lowering front-back pressure drag of the object. Moreover, adding a circumferential flow plate is also an effective flow control method. As Figure 1a shows, many scholars [13-19] added a spoiler in the wake of a cylinder, and found that the drag reduction effect and the vortex shedding frequency are strongly associated with the spoiler length. Anderson et al. [17] discovered that the drag coefficient can be reduced by roughly $30 \%$ at most when the length of the circumferential flow plate is equivalent to the cylinder diameter according to numerical simulation. Besides, as shown in Figure 1b, Roshko et al. [20] carried out wind tunnel tests of cases existing a gap between the cylinder and spoiler. They concluded that the drag coefficient and vortex shedding frequency could achieve minimum values when the distance (between the spoiler leading edge and the cylinder trailing edge) is 2.3 times the cylinder diameter. Likewise, Hwang [21] found the same law during numerical simulation. Ozono [22] and Bearman et al. [23] also achieved the purpose of preventing vortex shedding by conducting a wind tunnel test on asymmetrically arranged cylinders and spoilers. In addition, Rathakrishnan et al. [24] revealed that $h / 4$ ( $h$ is the height of the rectangular cylinder) was the optimum distance between the cylinder and the plate, and the best drag reduction effect could be achieved when the spoiler was placed horizontally based on their experimental study of the rectangular cylinder.

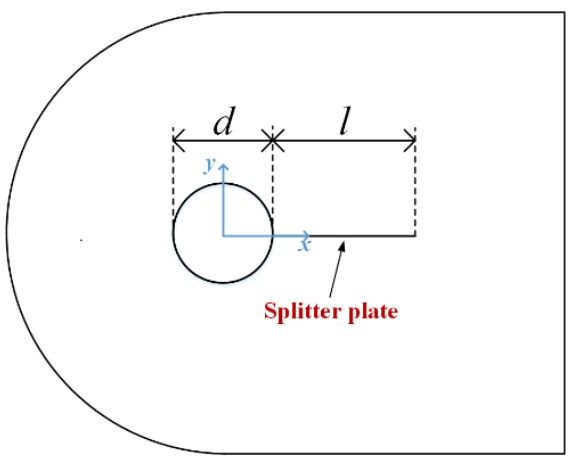

(a)

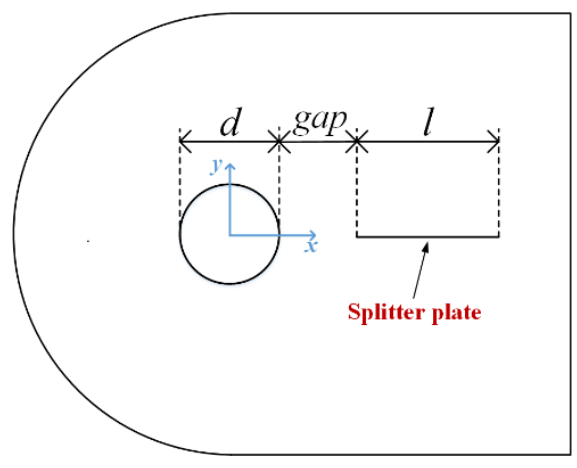

(b)

Figure 1. Schematic of the arrangement: (a) Cylinder-Spoiler; (b) Cylinder-Space-Spoiler.

In addition to the spoiler, methods of placing small-sized cylinders and symmetric airfoils similar to the spoiler in the cylindrical wake $[25,26]$ have also aroused the attention of scholars in recent years. Strykowski et al. [27] achieved the control of vortex shedding in the wake of the cylinder through placing a secondary small cylinder behind the cylinder, and disclosed that variations in the local flow field in the wake might affect the global characteristics. According to the literature [28], the addition of airfoil might affect the aerodynamic force and vortex street shape. Zhang et al. [29] found that not only were characteristics related the cylinder affected, but the lift-drag characteristics of the static airfoil in the wake of the cylinder also varied significantly. Furthermore, the maximum lift coefficient of the airfoil can be increased by $34 \%$ by adjusting the longitudinal distance between the airfoil leading edge and the center line of the wake.

The dynamic airfoil has a more significant impact on the wake of a cylinder in the cylindrical-airfoil tandem configuration apart from the static airfoil. Gopalkrishnan et al. [30] detected three varied flow modes in the airfoil wake from the experimental study on the phase difference between the airfoil motion and the vortex street. After the numerical simulation, Streitlien et al. [31] discovered that the cylinder-airfoil tandem configuration presented the least drag when the flapping phase was consistent with the vortex phase in the case of the airfoil carrying out parallel and pitching oscillations. Chao et al. [32] performed numerical simulation on a swing airfoil placed on the center line of two parallel semi-cylinders and discovered that the propulsion efficiency was affected by lateral gap of semi-cylinders, the lateral distance between the semi-cylinder and the airfoil, 
as well as the swing frequency of the airfoil. Xiao et al. [33] added an airfoil-like foil behind the cylinder and made the foil swing in accordance with the "subcarangiform" motion model, and through numerical simulation, they found that the swing frequency was a vital factor affecting the lift-drag performance of the cylinder.

$$
z= \pm \frac{0.12}{0.20}\left(0.29690 \sqrt{x}-0.12600 x-0.35160 x^{2}+0.284330 x^{3}-0.10150 x^{4}\right)
$$

The abovementioned studies mainly focus on the aerodynamic characteristics and propulsion efficiency of the airfoil. However, studies on the aerodynamic performance of the cylinder and the drag reduction effect of combined configuration remain relatively scarce, and there is no detailed analysis on the vortex interaction in the flow field. Therefore, the supplement of the research on cylinder-airfoil wake is of great significance, and this paper adopts numerical simulations to conduct a detailed analysis about that. A NACA0012 airfoil, one of classical symmetrical wing models of aircraft (the airfoil profile is defined in Equation (1), $x \in[0,1]$ ), with pitching oscillation of small attack angle, is placed in the wake of a cylinder. With the dynamic airfoil, a novel drag reduction method is introduced, which is conducive to the engineering drag reduction. Then variations in the vortex shedding frequency and the drag coefficient of tandem configuration are studied through changing the oscillation frequency of the airfoil as well as the distance between airfoil leading edge and cylinder center $(x / D)$. On this basis, the interaction between the cylinder and the vortex around the airfoil is also analyzed. The mechanisms found in this paper may be helpful for the future engineering applications, e.g., in launch vehicles, ship masts, submarine pipelines, etc.

This paper is organized as follows. To begin with, physical models and numerical methods are introduced in Section 2 together with the independent analysis of mesh and verification of numerical methods. Then, the influences of the airfoil oscillation period on the vortex shedding and drag of the cylinder are analyzed in Section 3. Moreover, here, we analyze the situation whereby the distance between airfoil leading edge and cylinder center is different and investigate the vortex interaction in the flow field. Finally, conclusions are made in Section 4.

\section{Verification of Physical Model and Numerical Method}

\subsection{Physical Model}

This paper studied the two-dimensional cylinder-airfoil tandem configuration, and the computational domain is shown in Figure 2. Specifically, the cylinder diameter $D$ is $100 \mathrm{~mm}$, and the airfoil chord length is equal to the cylinder diameter $(l / D=1.0)$. Besides, NACA0012 airfoil chord along the $x$-axis and the distance between airfoil leading edge and cylinder center $(x / D)$ can be adjusted. Furthermore, the radius of the computational domain is set as $20 D$, so as to remove the influence of boundary conditions of subsonic velocity. The NACA0012 airfoil located downstream oscillates along the $1 / 4$ chord point in pitch, and its attack angle is changed as in Equation (2):

$$
\alpha=\Delta \alpha+\alpha_{m} \sin \omega t
$$

where $\triangle \alpha$ is the average attack angle and $\alpha_{m}$ is the oscillation amplitude. 


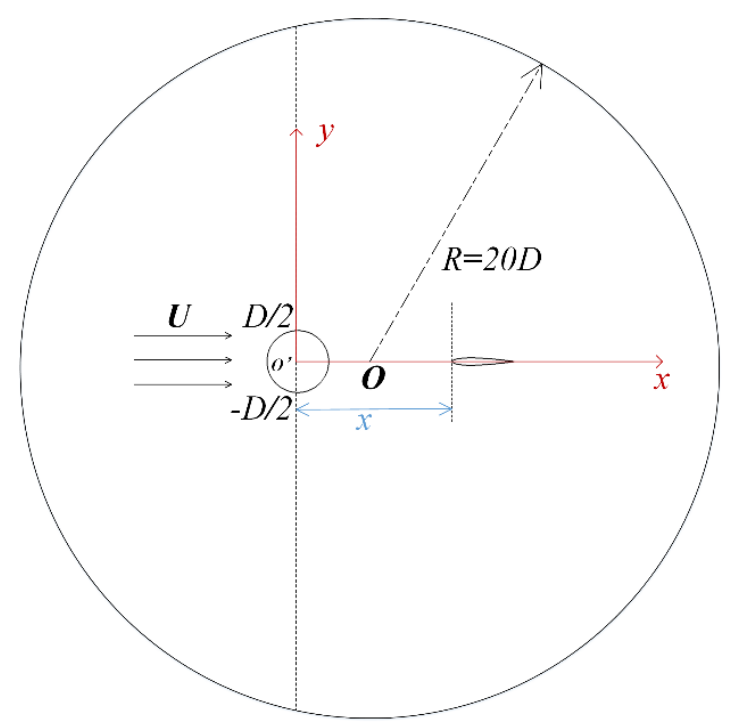

Figure 2. Schematic of the computational domain.

Regarding the classical problem of flow past a cylinder, flow in the case of $300 \leq \operatorname{Re}<2 \times 10^{5}$ is normally considered as in the sub-critical zone. In this study, the Reynolds number is set as 5000. Under this condition, the laminar flow in the upstream boundary layer of the cylinder has converted to turbulent flow, together with the wake transforming into turbulent vortex street, which can promote the separation of the airfoil boundary layer for better flow observation, and this can be the inflow condition for the downstream airfoil. Specific parameters of the flow field are presented in Table 1.

Table 1. Computational parameters.

\begin{tabular}{cc}
\hline Variable Name & Value \\
\hline Mach number $(M a)$ & 0.2 \\
Reynolds number $(R e)$ & 5000 \\
Inflow velocity $\left(U_{\infty}\right) / \mathrm{m}^{-1} \mathrm{~s}^{-1}$ & 34.0 \\
Inflow temperature $\left(T_{\infty}\right) / \mathrm{K}$ & 300 \\
Wall temperature $\left(T_{w}\right) / \mathrm{K}$ & 294 \\
Average attack angle $(\Delta \alpha) /{ }^{\circ}$ & 0 \\
Oscillation amplitude $\left(\alpha_{m}\right) /^{\circ}$ & 2.44 \\
\hline
\end{tabular}

\subsection{Numerical Methods}

The NACA0012 airfoil with forced pitching oscillation is related to the motion of mesh boundary. For accurately describing the flow of moving boundary, a coordinate system is established based on the arbitrary Lagrangian-Eulerian (ALE) method. In the ALE coordinate system, the governing equation in the integral form can be expressed as Equation (3):

$$
\frac{\partial}{\partial t} \int_{V} \boldsymbol{U} d V+\oint_{S}\left(\boldsymbol{F}-\boldsymbol{U} \boldsymbol{v}_{g} \cdot \boldsymbol{n}\right) d S=\oint_{S} \boldsymbol{F}^{v} d S,
$$

where $\boldsymbol{U}$ represents the conservation vector; $\boldsymbol{F}$ and $\boldsymbol{F}^{v}$ denote the non-viscous flux and viscous flux, respectively; $v_{g}$ symbolizes the velocity of moving boundary; $d S$ and $d V$ stand for the surface area and volume of the control volume; and $\mathrm{n}$ points to the direction of exterior normal of the control volume surface.

The calculation in this paper is based on the finite volume method, which is more flexible and fast-solved than other discrete methods, and this method is applied by many popular CFD software programs, such as FLUENT, CFX, etc. Besides, the one-equation SA turbulence model [34], suitable for simulating the turbulence on unsteady dynamic motion characteristics at low speed, is adopted for flow simulation, and the computation quantity 
of the model is lower compared to other turbulent models. Besides, the non-viscous and viscous fluxes are differentially split in the Roe format [35]. In addition, the dual-time-step and LU-SGS implicit marching method [36] are used for the time term by setting the number of sub-iteration steps as 80 .

The Navier-Stokes (NS) equations in the ALE coordinate system interact with the dynamics / kinematics equations, controlling the motion of the airfoil by tight coupling. The tightly coupled marching-iteration strategy is presented in Figure 3, where CFD (computational fluid dynamics) is the solution of NS equations and RBD (rigid body dynamics) is the solution of flight dynamic and kinematic equations. These methods have been integrated into our unsteady RANS solver. For more details, please refer to the work of Zhang and Wang [37] and Chang et al. [38].

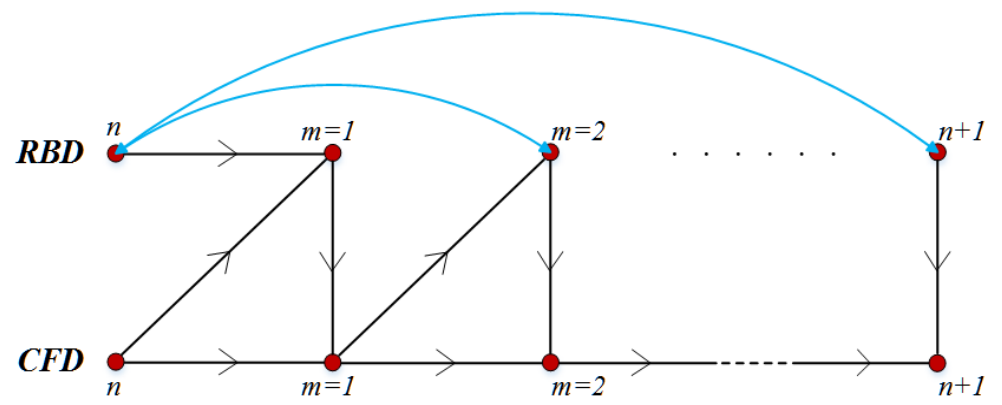

Figure 3. Sketch of data exchanges in fully implicit coupling computation.

\subsection{Mesh Generation}

The dynamic overlapping grid technique [39] is utilized to handle the moving boundary problem during computation. Essentially, since there might be overlapping and nesting areas between mesh blocks generated separately by varied objects, necessary pre-treatment should be performed on mesh blocks before computation. Then, a transitive relationship should be established on the boundary of the overlapping area, so that the boundary information can be updated through exchanging data interpolation during computation. On this basis, the solution of the total flow field can be obtained when time marching has been conducted.

The grids are composed of a cylinder mesh, a mesh near the airfoil, and a background mesh. Among them, the background mesh covers the whole computational domain. Furthermore, the mesh can be divided into structured and unstructured hybrid meshes in accordance with Figure 4a,b. Specifically, quadrilateral mesh and triangular mesh are adopted for the body-fitted mesh near the cylinder as well as airfoil walls, respectively. To seize the viscous boundary layer more accurately, the body-fitted quadrilateral mesh is equipped with more than 20 layers. Moreover, the mesh near the object is properly encrypted in the background mesh, so that the flow field around the object can be displayed more subtly. Besides, the mesh is processed into blocks before computation for conducting parallel calculation and improving the computational efficiency. More precisely speaking, cylinder, airfoil, and background meshes are partitioned into 16 blocks, respectively, as shown in Figure 4c.

\subsection{Verification of Numerical Method}

When carrying out the verification of mesh independence, three sets of meshes are adopted for simulating the shape of a single cylinder. The first layer height of mesh and mesh volume of the corresponding wall are displayed in Table 2. With the mesh being encrypted, the vortex shedding period in the wake of a cylinder is unchanged, presenting certain convergence. To improve the computational efficiency, the medium-density mesh is applied in this paper on the premise of safeguarding the accuracy of results. 


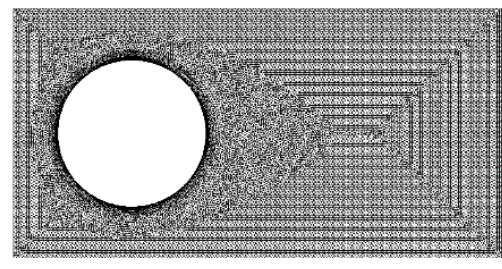

(a)

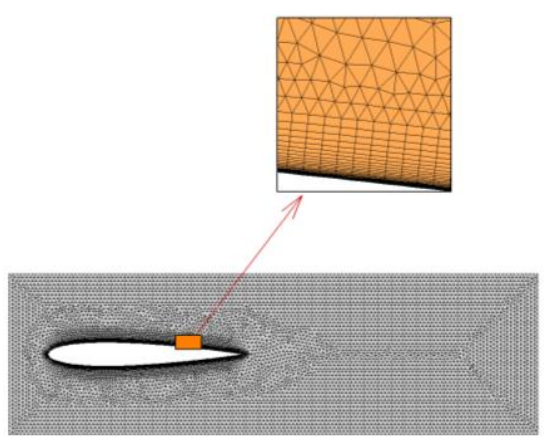

(b)

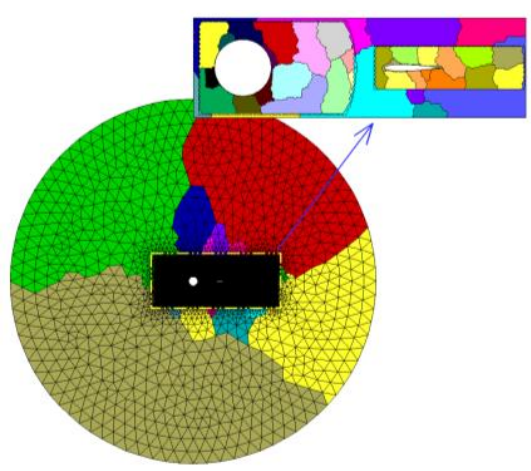

(c)

Figure 4. Grid setup and partition: (a) Cylinder mesh; (b) NACA0012 airfoil mesh; (c) Mesh partition.

Table 2. Mesh settings of cylinder.

\begin{tabular}{cccc}
\hline Characteristic & $\boldsymbol{\Delta} \boldsymbol{x} / \mathbf{m m}$ & Mesh Quantity & $\begin{array}{c}\text { Vortex Shedding } \\
\text { Period (T)/s }\end{array}$ \\
\hline Coarse & 0.01 & 38391 & 0.204 \\
Moderate & 0.001 & 42417 & 0.208 \\
Refined & 0.0005 & 44232 & 0.208 \\
\hline
\end{tabular}

Moreover, pitching oscillation for the NACA0012 airfoil (past the 1/4 chord point) experimental results, published by AGARD (Advisory Group for Aerospace Research and Development) of NATO (North Atlantic Treaty Organization) in 1982, [40], are adopted for verifying the dynamic computational performance of the numerical method in this paper.

Firstly, the steady flow field at the average attack angle is calculated for the initial field of unsteady simulation. The lift coefficient varying with the attack angle is shown in Figure 5, incorporating the experimental results of Landon [40] and numerical results of other researchers [41]. The computational result of this paper agrees well with the numerical simulation results in the literature, and is basically identical with the distribution of the experimental results. This proves that the numerical method used in this paper can accurately simulate the pitching oscillation of the NACA0012 airfoil at a small attack angle.

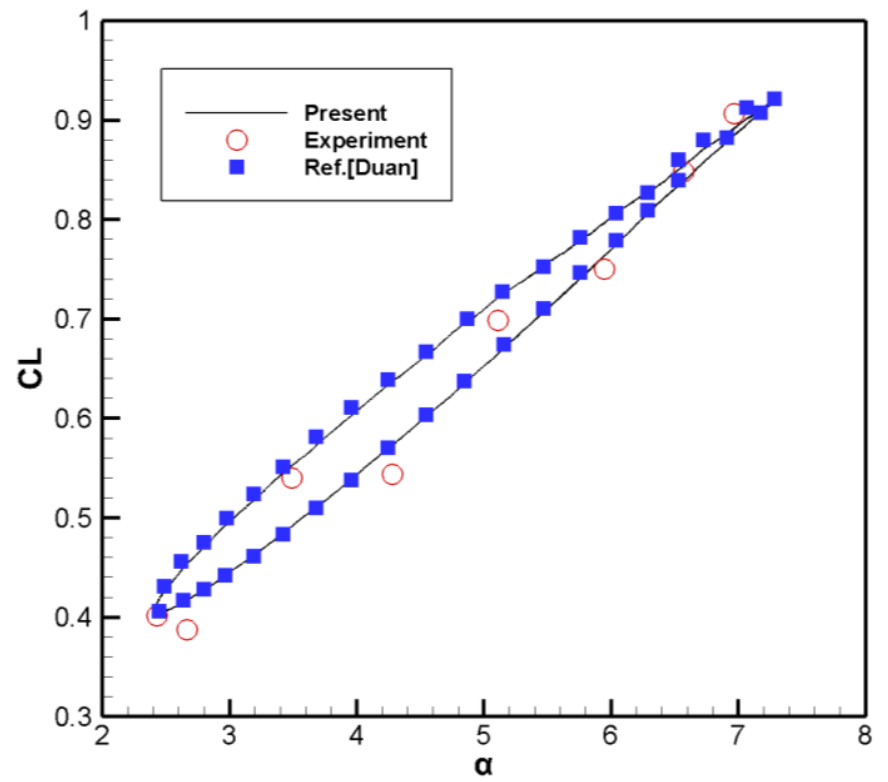

Figure 5. Lift coefficients varying with attack angle. 


\section{Results}

\subsection{Effect of $T / T_{0}$}

When the Reynolds number is between 500 and $2 \times 10^{5}$, the Strouhal number $(S t)$ of flow past a cylinder will basically remain unchanged at 0.2 . The vortex shedding period $T_{0}$ can be calculated by Equation (4), and the airfoil oscillation period is $T$.

$$
\left\{\begin{array}{c}
S t=\frac{f D}{U_{\infty}} \\
T_{0}=\frac{1}{f}
\end{array},\right.
$$

where $D$ represents the cylinder diameter and $U_{\infty}$ notes the velocity of free inflow.

This section discusses the influence of $T / T_{0}$ (the ratio of the airfoil oscillation period to the vortex shedding period of a single cylinder) on the tandem configuration. Computational results and analysis are presented in the following two subsections.

\subsubsection{Influence on Vortex Shedding Frequency}

Aerodynamic characteristics of the airfoil and cylinder are changed periodically under the combined effect of the airfoil oscillation and the cylindrical wake. Concretely, the aerodynamic coefficients' frequencies of the cylinder and airfoil vary with the increase of $T / T_{0}$, as shown in Figure 6a. When $T / T_{0}$ is less than roughly 0.2 , the frequency oscillation modes of cylinder and airfoil also change, and the smaller the $T / T_{0}$, the greater the difference. Besides, when $T / T_{0}$ is greater than the critical value, the frequencies of both are coupled, which is called "aerodynamic coupling" in this paper.

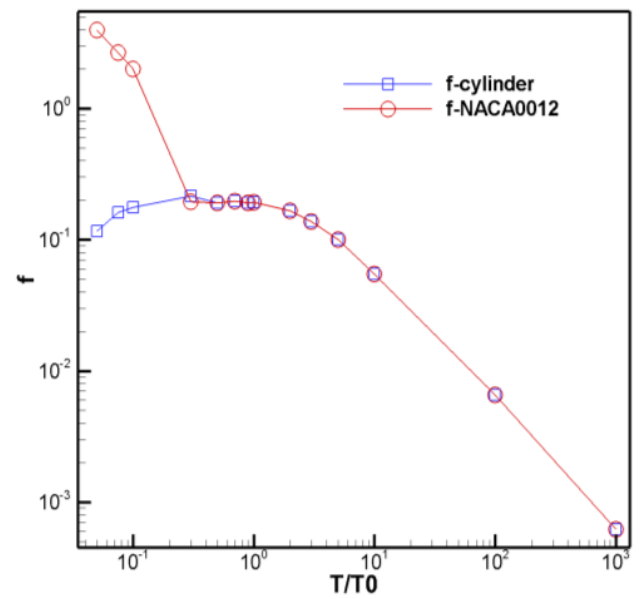

(a)

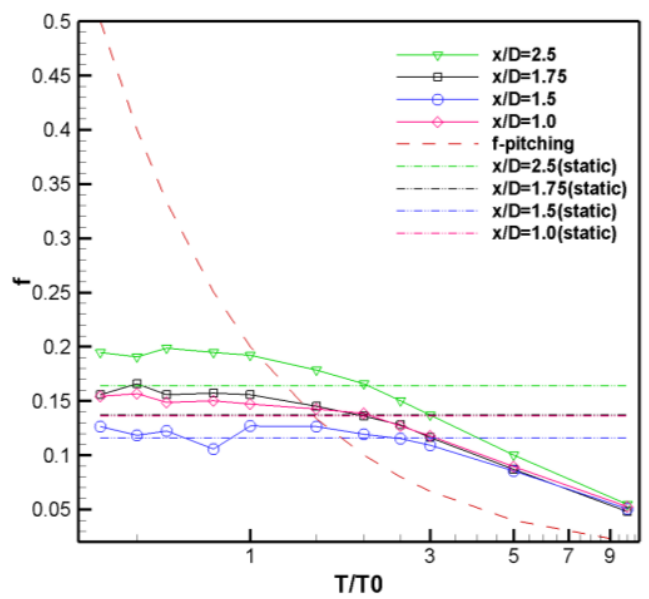

(b)

Figure 6. The frequency of lift coefficient varying with $T / T_{0}$ : (a) The frequency of airfoil and cylinder $(x / D=2.5) ;(b)$ Coupled frequency.

The coupling frequency of lift coefficient varying with various airfoils and $x / D$ is shown in Figure $6 \mathrm{~b}$, comparing with the variation frequency of the static cylinder lift coefficient. As $T / T_{0}$ increases, the coupling frequency will decrease. The coupling frequency and static results have little difference under high-frequency oscillation of the airfoil, whereas the former approaches the airfoil oscillation frequency at low-frequency oscillation. It is evident that spectral characteristics in the wake of a cylinder have a greater influence on the airfoil low-frequency oscillation.

To investigate critical factors of aerodynamic coupling, fast Fourier analysis (FFT) is performed on the instantaneous lift coefficients of the cylinder and airfoil. Furthermore, the amplitudes corresponding to the fundamental frequencies of both are calculated, the ratio of which is presented in Figure 7 . The results show that the ratio gradually decreases with the increase of $T / T_{0}$, and a turning point appears when $T / T_{0}=0.3$, that is, the variation 
trend of the ratio slackens in the presence of aerodynamic coupling. By inference, the amplitude ratios of the cylinder and airfoil aerodynamic coefficients corresponding to the fundamental frequency represent a critical factor affecting aerodynamic coupling. When the ratio is less than a critical value (it is about 1.5 when $x / D=1.5$; note that the critical value is varied along with the variation of $x / D$ ), aerodynamic coupling will occur in the corresponding flow field.

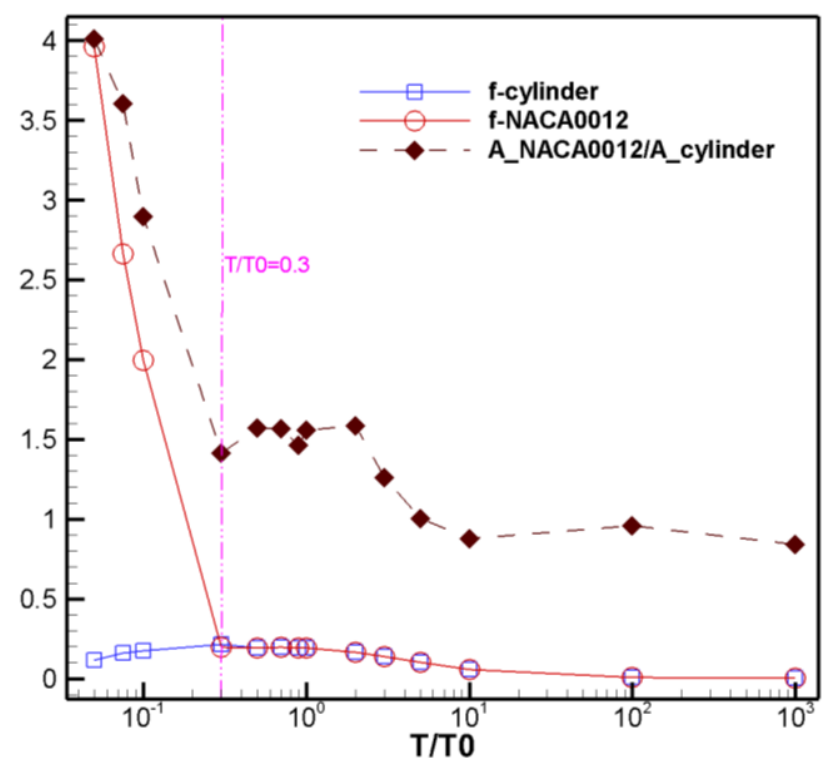

Figure 7. Lift coefficient frequency and amplitude ratio of cylinder and airfoil $(x / D=2.5)$.

\subsubsection{Influence on Drag Reduction Characteristics}

When $T / T_{0}>0.2$, aerodynamic coupling is observed in the flow field. At this time, airfoil oscillation has a significant impact on the wake of a cylinder. Subsequently, the drag reduction effect of tandem configuration $\left(T / T_{0} \in[0.4,10]\right)$ is analyzed, and the mean drag coefficient value of a single cylinder is computed (1.6087).

Figure 8 indicates that the relationship between the drag reduction rate of tandem configuration and $T / T_{0}$ is related to $x / D$ (the distance between the airfoil leading edge and the cylinder center). Moreover, two completely different tendencies before $x / D=1.5$ and after $x / D=1.75$ are presented in the curve of drag reduction. To be specific, when $x / D \leq 1.5$, the drag reduction rate varies slightly, which can reach above $45 \%$ within the studied range. When $x / D \geq 1.75$, the drag reduction rate is relatively small, reaching $30 \%$ at most. As $T / T_{0}$ increases, the drag reduction rate increases at first, and then decreases with the maximum value taken around $T / T_{0}=2$. The reasons are shown in Section 3.2.

The above variations are explained below in combination with flow fields when $x / D=1.0$ and $x / D=2.5$, respectively. As can be observed from Figure 9, there is a relatively short distance between the cylinder and the airfoil when $x / D=1.0$. Thus, the airfoil is surrounded by the wake vortex of the cylinder and no Karman vortex street is formed between both. Moreover, with the strong wake vortex of the cylinder, the airfoil oscillation has a relatively small effect on the flow field. Therefore, the drag coefficient varies little when $T / T_{0}$ changes. 


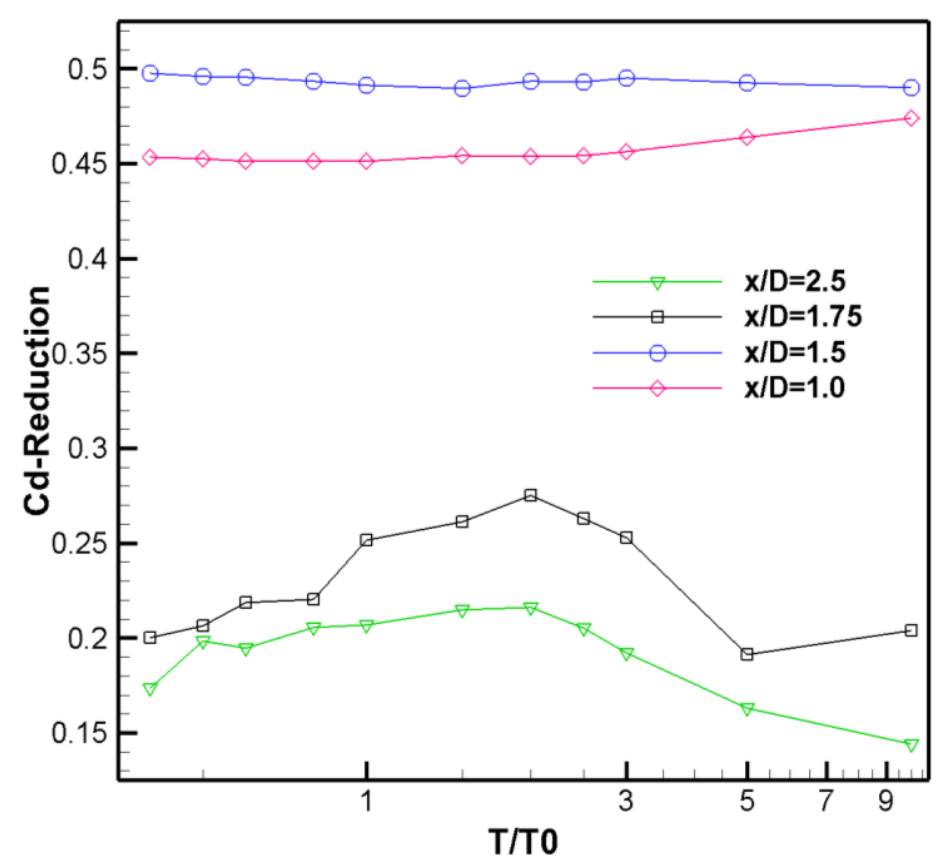

Figure 8. Drag reduction of the tandem configuration varying with $T / T_{0}$.

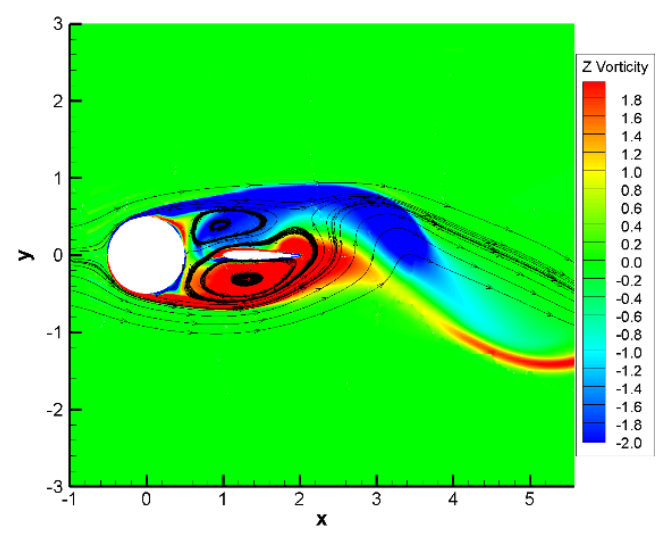

(a)

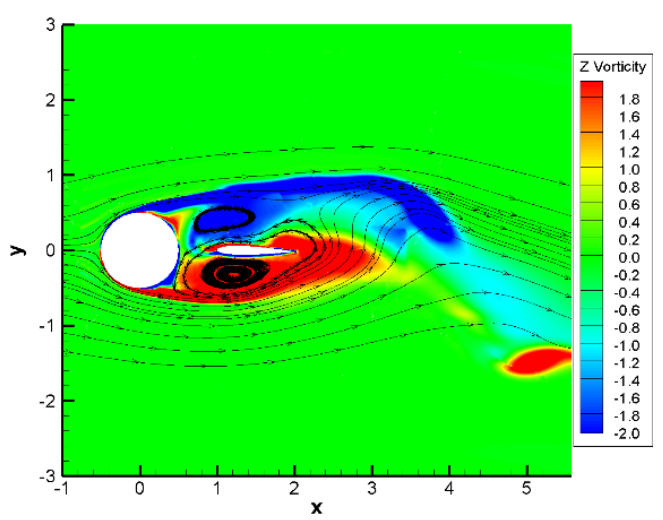

(b)

Figure 9. Vorticity contour at the moment of drag coefficient amplitude $(x / D=1.0):(a) T / T_{0}=2.0$; (b) $T / T_{0}=5.0$.

Pressure contour and pressure coefficient of the cylinder wall at $x / D=2.5$ are displayed in Figure 10 ( $\varphi=0$ represents the cylindrical wall when $x=-0.5$, and $\varphi$ increases clockwise). A low-pressure area can be observed at the trailing edge of the cylinder (partially $y<0$ ). When $T / T_{0} \leq 2.0$, the increase in the oscillation period will suppress the development of the low-pressure area. The pressure difference between the first half $\left(\varphi \in\left[0^{\circ}, 90^{\circ}\right] \cup\left[270^{\circ}, 360^{\circ}\right]\right)$ and second half of the cylinder $\left(\varphi \in\left[90^{\circ}, 270^{\circ}\right]\right)$ gets lowered gradually. On the contrary, when $T / T_{0} \geq 2.0$, the increase in the oscillation period will promote the development of the low-pressure area. In addition, together with the rising pressure difference between the front and back surfaces of the cylinder, the drag reduction rate will decline.

\subsection{Effect of $x / D$}

Through analyzing the influence of $T / T_{0}$, it is apparent that $x / D$ (the distance between the airfoil leading edge and cylinder center) has a significant influence on the flow characteristics. 
$T / T_{0}=0.5$
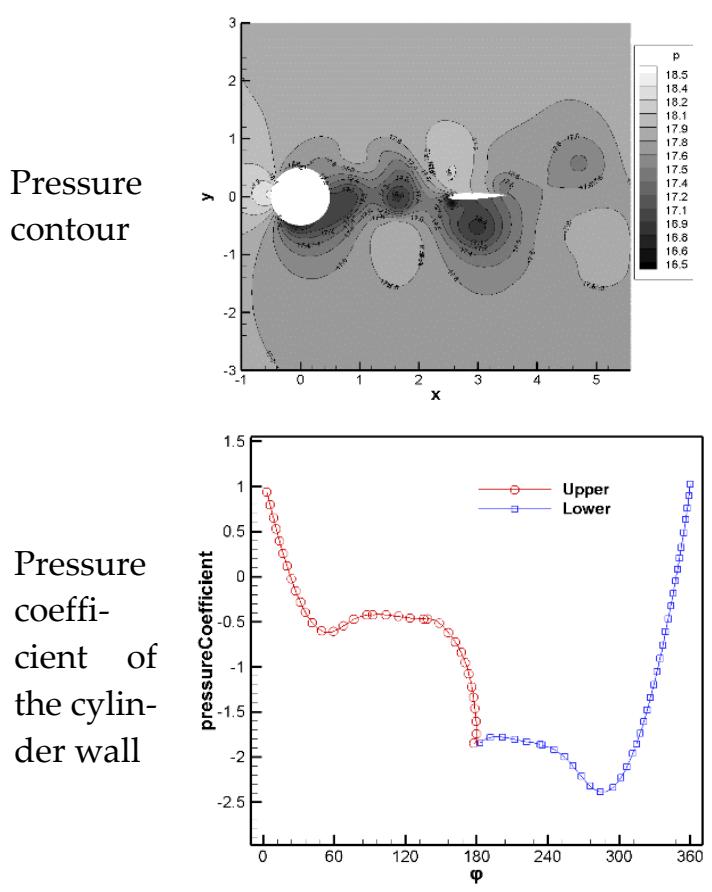

$T / T_{0}=2.0$
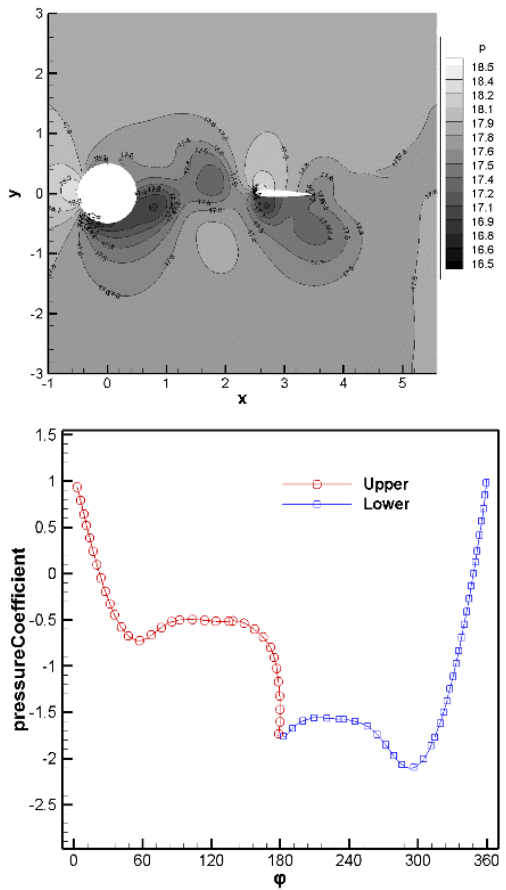

$T / T_{0}=5.0$
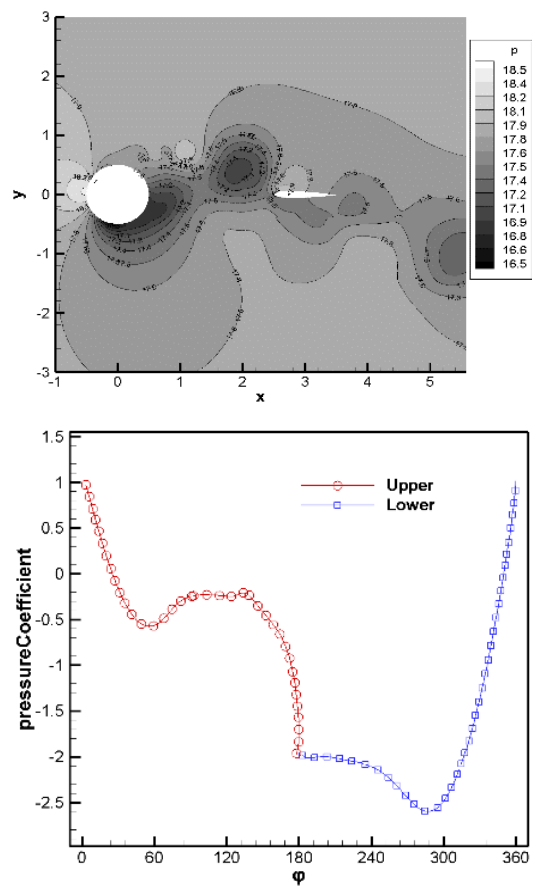

Figure 10. Pressure contour and pressure coefficient of the cylinder wall at the moment of drag coefficient amplitude $(x / D=2.5)$.

\subsubsection{Influence on the Flow Mechanism}

According to computational results listed in Section 3.1.2, drag characteristics of tandem configuration before $x / D=1.5$ and after $x / D=1.75$ are completely different. Hence, evolutions of the flow field when $x / D=1.0$ and $x / D=1.75$ are selected for following discussion.

The vorticity contour when $x / D=1.0$ is displayed in Figure 11. At this moment, there is no complete Karman vortex street between the cylinder and the airfoil. Specifically, $t_{0}-t_{5}$ represent different evolution stages of the flow field respectively.

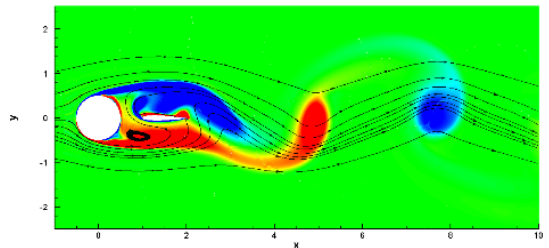

(a)

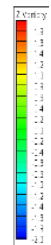

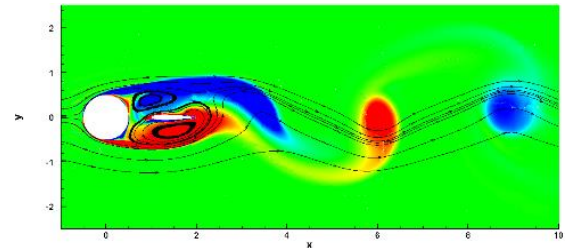

(b)

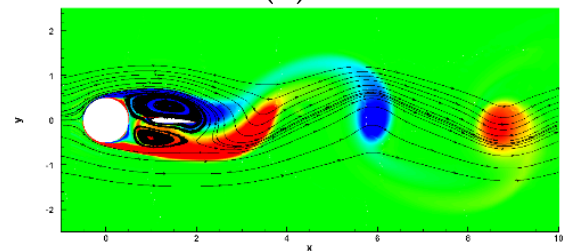

(e)

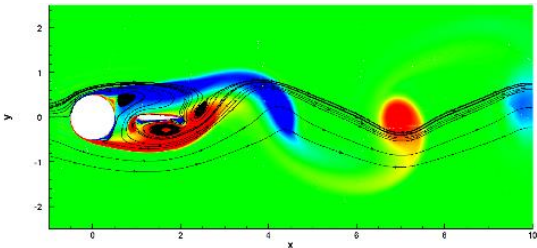

(c)

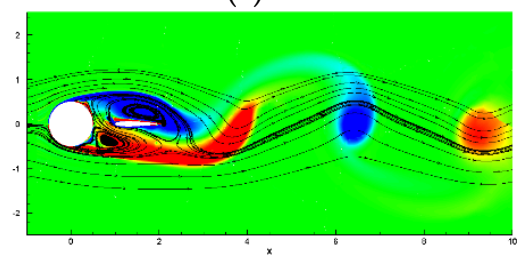

(f)

Figure 11. The flow mechanism $\left(x / D=1.0, T / T_{0}=0.5\right)$ : (a) $t_{0} ;$ (b) $t_{1} ;$ (c) $t_{2} ;$ (d) $t_{3} ;(\mathbf{e}) t_{4} ;(\mathbf{f}) t_{5}$. 
The wake vortex of the cylinder in the flow field can be called the "primary vortex" for its dominating effect. Taking the local flow field of $y<0$ as an example, when the primary vortex meets the NACA0012 airfoil, since the vortex length is far greater than the airfoil chord length, the latter is wrapped by the primary vortex, as shown in Figure $11 \mathrm{~b}$. When the primary vortex marches to the middle of the airfoil, a low-pressure area will form, causing the induced vortices generated in the trailing and leading edges of the airfoil successively, as shown in Figure 11c. In the meantime, the airfoil, like a vortex separator, can divide the primary vortex into two parts. As can be observed from Figure 11d, a part of vortex is fused with the induced vortex generated by the upper airfoil in the trailing edge, while the other part is fused with the induced vortex developed at the lower airfoil in the leading edge. After that, the new primary vortex flows past the upper airfoil, as shown in Figure 11e. The direction of the primary vortex at the upper airfoil is opposite to the residual vortex at the lower airfoil, and the primary vortex at the upper airfoil expands and pushes the vortex at the lower airfoil to move along the opposite direction of inflow and collide with the cylinder surface, as shown in Figure 11f. Next, the flow separation at the $y<0$ section is aggravated. Hence, the vortex that is pushed to the surrounding wall is accumulated, forming a new primary vortex to repeat the above process.

When $x / D=1.75$, the flow mechanism will be changed significantly. For example, a complete Karman vortex street is formed between the cylinder and the airfoil. In Figure 12, red and blue contours represent the counterclockwise vortex and clockwise vortex respectively. Firstly, the vortex street breaks down resulting from the effect of the airfoil. After that, most of the vortex street continues to march along the lower side of the airfoil, while a small part is offset by the vortex in the opposite direction of the upper airfoil. When the vortex is in the middle of the airfoil, induced vortices will be generated in the leading edge of the airfoil, as shown in Figure 12b. Under the effect of airfoil, the vortex at the lower airfoil is divided into two vortices. Then, the first half is fused with the induced vortex, and the second half is fused with the small vortex shedding from the upper surface. Meanwhile, another induced vortex arises at the tail region of airfoil, as shown in Figure 12c. Afterwards, the trailing edge induced vortices gradually develop and trigger the vortex-breakdown at the lower side. By this time, vorticity of the induced vortex after fusion at the leading edge gets increased, as shown in Figure 12d. Influenced by this, the near-wall vortex rolls up near the airfoil. As shown in Figure 12e, the near-wall vortex spreads to the opposite side of the airfoil and fused with that on the opposite side, while the vortex in the lower surface of the airfoil spreads downstream. In Figure $12 f$, the induced vortex shedding from the trailing edge is fused with that in the upper airfoil, and the vortex breakdown at the lower airfoil is fused again after shedding and will advance downstream.

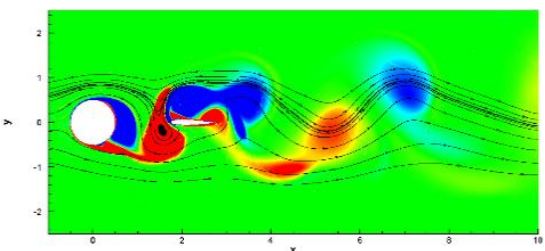

(a)

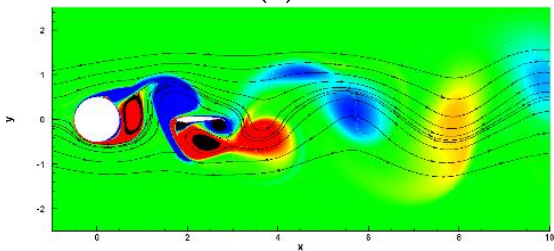

(d)

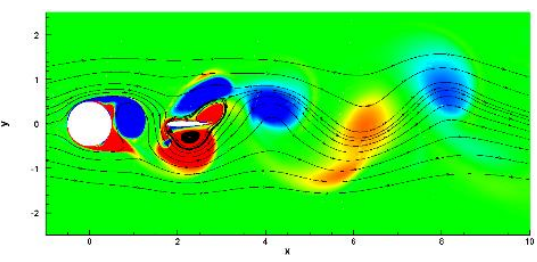

(b)

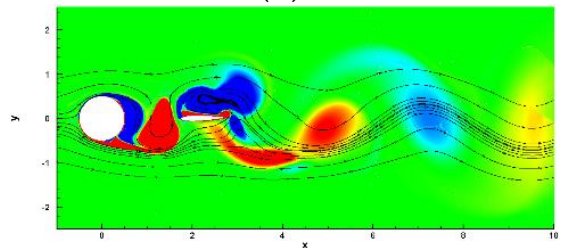

(e)

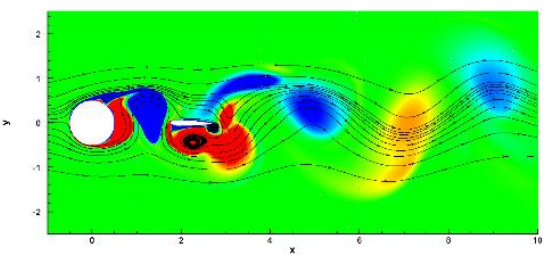

(c)

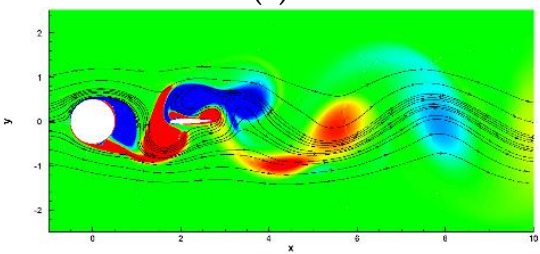

(f)

Figure 12. The flow mechanism $\left(x / D=1.75, T / T_{0}=0.5\right)$ : (a) $t_{0} ;(\mathbf{b}) t_{1} ;(\mathbf{c}) t_{2} ;$ (d) $t_{3} ;$ (e) $t_{4} ;$ (f) $t_{5}$. 


\subsubsection{Influence on the Vortex Shedding Frequency}

Since the airfoil oscillation upon aerodynamic coupling has a greater influence on the wake of the cylinder, three groups of varied $T / T_{0}$ values after the critical period are selected for the study in this section, that is, $T / T_{0}=0.5,1.0,2.0$. The variation of the coupling frequency with $x / D$ is shown in Figure 13. It can be seen that the three groups of varied $T / T_{0}$ present the same variation trend. When $x / D \leq 1.6$, the coupling frequency will gradually decrease as $x / D$ increases, with the minimum coupling frequency at roughly $x / D=1.6$. Besides, when $x / D \geq 1.625$, the coupling frequency will be on the rise, and when $x / D>3.5$, the coupling frequency will become stabilized.

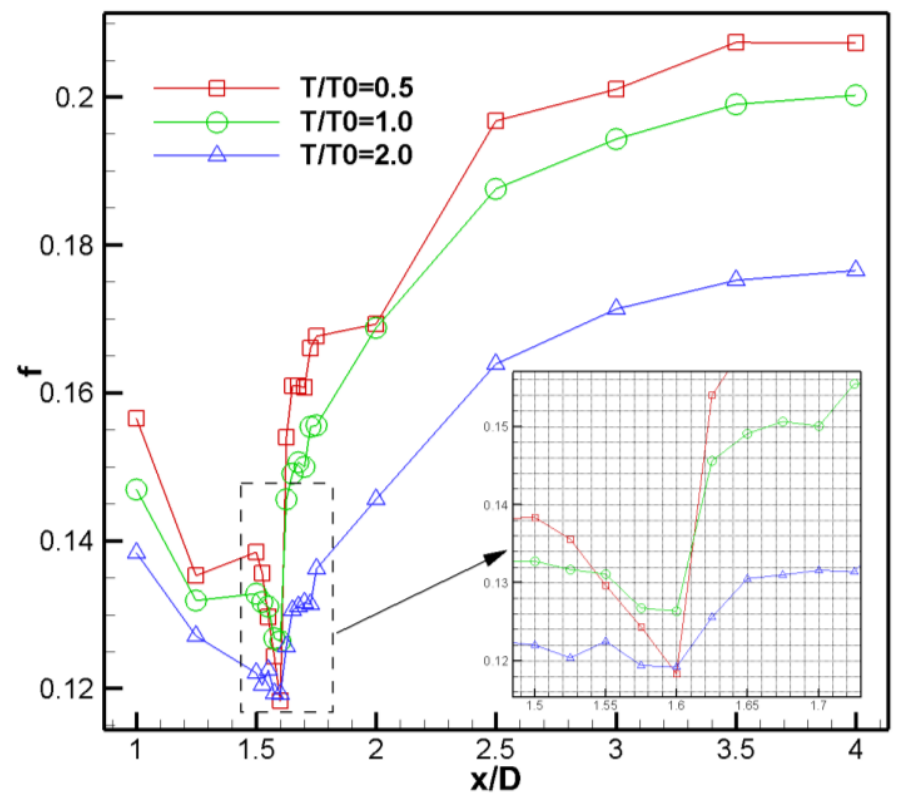

Figure 13. Coupling frequency varying with $x / D$.

The above variations are explained in combination with flow fields of varied $x / D$. As can be seen from Figure 14, there is a significant variation in the flow fields when $x / D=1.6$ and 1.625. More precisely, when $x / D=1.6$, the airfoil surrounded by the wake vortex of the cylinder dominates the flow field. When $x / D=1.625$, a counter-rotating and alternately shedding vortex street are formed between the cylinder and the airfoil.

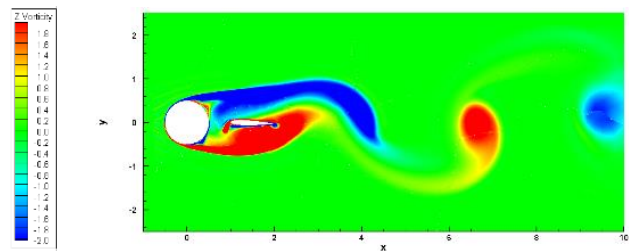

(a)

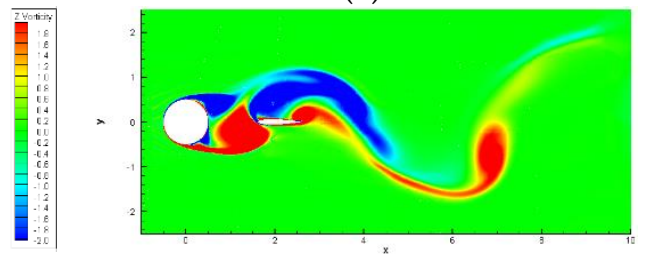

(d)

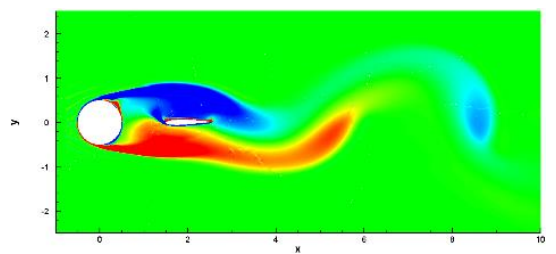

(b)

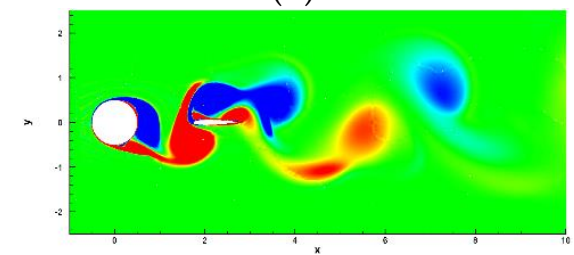

(e)

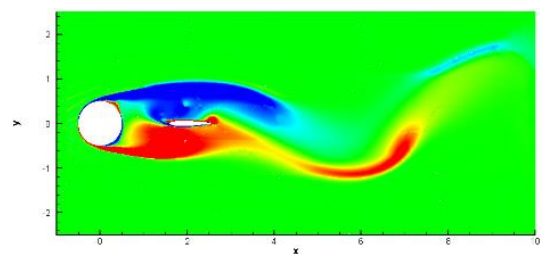

(c)

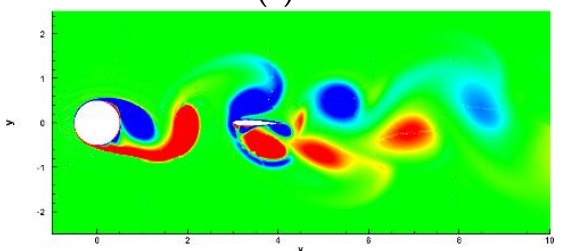

(f)

Figure 14. Vorticity contour with different $x / D$ : (a) $x / D=1.0 ;(\mathbf{b}) x / D=1.5 ;$ (c) $x / D=1.6 ;$ (d) $x / D=1.625 ;(\mathbf{e}) x / D=1.75$; (f) $x / D=3.0$. 
When $x / D \leq 1.6$, the wake vortex of the cylinder is fully developed with the rising $x / D$. In this case, longer time for the vortex interaction with the airfoil is required as the length of vortex increases, so as to form a relatively stable vortex to shed from the airfoil trailing edge, as shown in Figure $14 \mathrm{a}-\mathrm{c}$. Consequently, the distance between the initial shedding position of the vortex and the airfoil trailing edge increases gradually, together with the decline in coupling frequency. When $x / D \geq 1.625$, a stable Karman vortex street forms between the cylinder and the airfoil. Moreover, as $x / D$ increases, the vortex street is dissipated before flowing past the airfoil, leading to a decrease in the strength of the vortex street, along with shorter interaction time with the airfoil. As depicted in Figure 14d-f, the distance between adjacent vortices in the airfoil wake reduces with the growth of coupling frequency.

\subsubsection{Influence on Drag Reduction Characteristics}

The relationship between the drag reduction rate and $x / D$ of the cylinder-airfoil tandem configuration under three different $T / T_{0}$ conditions is presented in Figure 15 . The results show that the drag characteristics varying with $x / D$ is basically unrelated to $T / T_{0}$. When $x / D \leq 1.6$, the drag reduction rate is on the rise with the increase of $x / D$, reaching more than $49 \%$ when $x / D=1.6$. After $x / D \geq 1.625$, the drag reduction rate falls abruptly and then becomes stabilized. Around $x / D=1.6$, a large variation is witnessed in the drag reduction rate of tandem configuration, which corresponds to the conclusion made in Section 3.1.2.

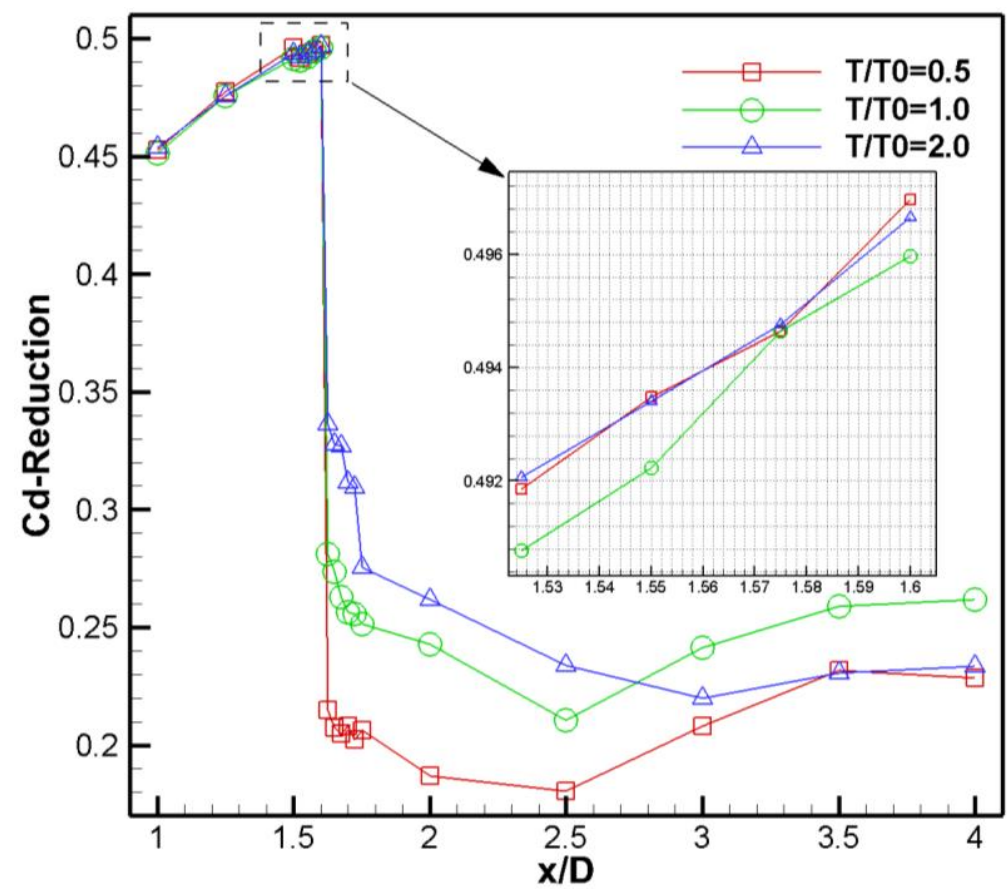

Figure 15. Drag Reduction of tandem configuration varying with $x / D$.

Evolutionary conditions of the flow field are analyzed in Section 3.2.1. The flow mechanism in the case of $x / D \leq 1.6$ is similar to that of $x / D=1.0$. Figure 16 depicts the pressure contour of flow fields when $x / D=1.0,1.25$ and 1.5. Apparently, the distance between the primary vortex core and the cylindrical wall on the same side increases with the increase of $x / D$, together with a low pressure intensity at the center of vortex core. Consequently, when $x / D \leq 1.6$, the pressure drag will decrease gradually with the rising drag reduction rate. 

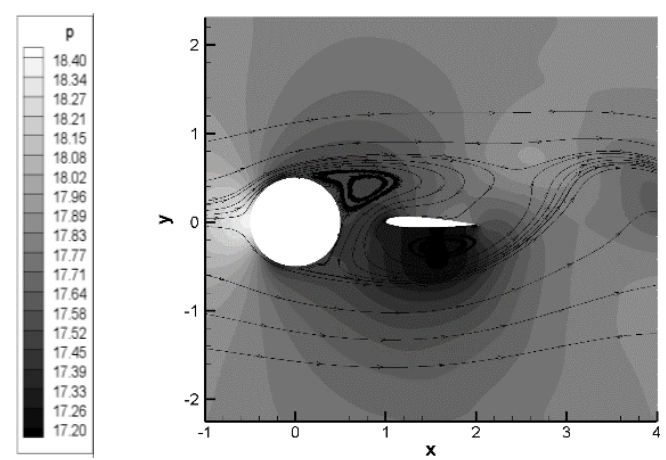

(a)

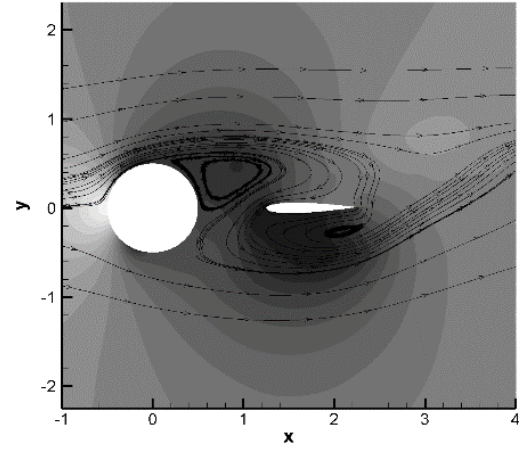

(b)

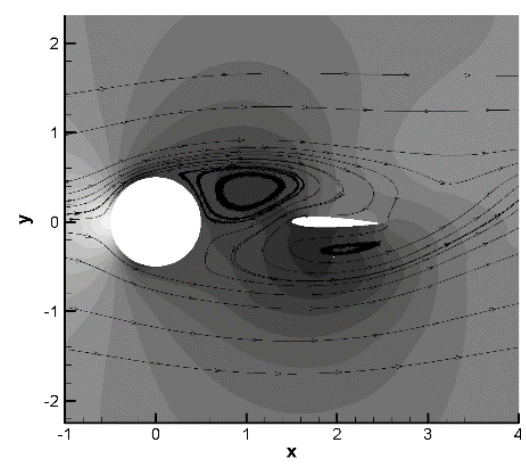

(c)

Figure 16. Interaction between vortex from upper and lower surfaces $\left(T / T_{0}=0.5\right):(\mathbf{a}) x / D=1.0 ;(\mathbf{b}) x / D=1.25 ;(\mathbf{c}) x / D=1.5$.

Comparing flow fields of $x / D \geq 1.625$ and $x / D \leq 1.6$, the main difference will be witnessed between the cylinder and the airfoil. When $x / D \geq 1.625$, the phenomenon of Karman vortex street shedding is found. Since the vortex street has a great effect on the low-pressure area behind the cylinder, there will be an abrupt increase in the time-averaged drag coefficient of tandem configuration near $x / D=1.6$.

The pressure contour of flow fields in different $x / D$ s when $T / T_{0}=0.5$ is displayed in Figure 17. As $x / D$ increases, the strength of the Karman vortex street also increases. It can be seen that the time-average drag coefficient increases slightly after $x / D=1.625$. When $x / D$ increases further, the Karman vortex street will expand downstream and become stabilized. At the same time, its resulting low-pressure area has a weakening effect on the cylinder. Although the space between the cylinder and the airfoil is large enough to accommodate the third low-pressure area at $x / D=4.0$, the drag reduction effect is less affected for its large gap with the trailing edge of the cylinder. Therefore, the drag reduction rate of the tandem configuration remains unchanged after a small rise.

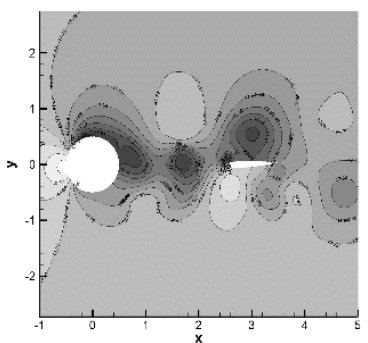

(a)

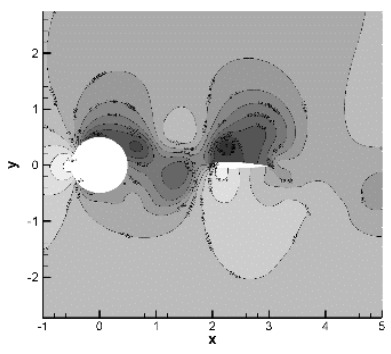

(b)

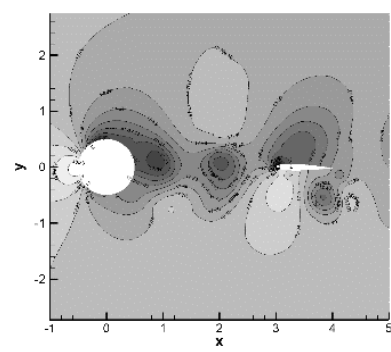

(c)

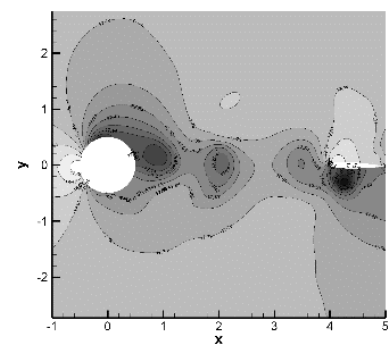

(d)

Figure 17. Pressure contour in different $x / D\left(T / T_{0}=0.5\right):(\mathbf{a}) x / D=1.75 ;(\mathbf{b}) x / D=2.0 ;(\mathbf{c}) x / D=3.0 ;(\mathbf{d}) x / D=4.0$.

\section{Conclusions}

A NACA0012 airfoil of pitching oscillation is placed downstream of the cylinder. Then, the flow state in the wake of the cylinder changes by changing the pitch oscillation of the airfoil, so as to adjust the distribution of the low-pressure area downstream of the cylinder. The influence of $T / T_{0}$ (the ratio of the airfoil oscillation period to the Strouhal period of the cylinder) and $x / D$ (the ratio of the distance between airfoil leading edge and cylinder center to the cylinder diameter) on the shedding frequency in the wake of a cylinder and the drag reduction effect of tandem configuration were studied, particularly on the flow mechanism of the flow field. Conclusions are made as follows:

1. When $T / T_{0}$ is greater than a critical value, the aerodynamic coefficients of the cylinder and the airfoil will vary in accordance with the same frequency, i.e., the phenomenon of "aerodynamic coupling" will occur. According to our simulation results, the ratio of 
the amplitudes corresponding to the aerodynamic coefficients' fundamental frequency of the cylinder and the airfoil is essential for aerodynamic coupling.

2. When $x / D \leq 1.5$, the drag reduction rate will vary slightly with the increase of $T / T_{0}$, reaching above $45 \%$. Conversely, when $x / D \geq 1.75$, a small drag reduction rate will be found (less than $30 \%$ ). As $T / T_{0}$ increases, the drag reduction rate will first increase and then decrease with the maximum value taken around $T / T_{0}=2.0$.

3. Evolutionary modes of the flow field before and after $x / D=1.6$ are various, too. When $x / D \leq 1.6$, the coupling frequency will decrease with the increase of $x / D$, and the smallest coupling frequency will be observed near $x / D=1.6$. The coupling frequency will be on the rise after $x / D \geq 1.625$, becoming stabilized after $x / D>3.5$, since the airfoil has a decreased suppression effect on vortex shedding.

4. When $x / D \leq 1.6$, influenced by the airfoil, complete vortex shedding cannot form at the trailing edge of the cylinder. Moreover, the primary vortex may result in a significant decline on the drag coefficient of the tandem configuration. The drag reduction rate at $x / D=1.6$ can reach above $50 \%$ (under the premise of pneumatic coupling). When $x / D \geq 1.625$, the alternately shedding vortex street will be observed between the cylinder and the airfoil, from which the drag coefficient of tandem configuration will sharply increase and then become stabilized with the rising $x / D$.

To sum up, $T / T_{0}$ and $x / D$ have a remarkable impact on the evolution of the cylinder wake and resistance characteristics of the combined configuration. The NACA0012 airfoil undergoing pitching oscillation in the cylinder wake is an effective means of flow control, which can achieve a more than $50 \%$ drag reduction rate for the tandem configuration. Apart from the drag reduction effect, it can also function as a spoiler to control the vortex shedding period. In addition, it provides a significant reference for studies concerning the drag reduction of rockets and other cylindrical devices.

Author Contributions: Conceptualization, R.H. and X.-L.Y.; methodology, X.-H.C.; software, X.-H.C.; validation, R.H.; formal analysis, R.H.; investigation, X.-L.Y.; resources, W.L.; data curation, R.H.; writing—original draft preparation, R.H.; writing—review and editing, R.H.; visualization, X.-L.Y.; supervision, X.-L.Y.; project administration, W.L.; funding acquisition, W.L. All authors have read and agreed to the published version of the manuscript.

Funding: This research was funded by the National Key Project of China, grant number GJXM92579. The APC was funded by GJXM92579.

Institutional Review Board Statement: Not applicable.

Informed Consent Statement: Not applicable.

Data Availability Statement: The data used to support the findings of this study are included in the article.

Conflicts of Interest: The authors declare no conflict of interest.

\section{References}

1. Ericsson, L.E.; Pavish, D. Aeroelastic vehicle dynamics of a proposed delta II 7920-10L launch vehicle. J. Spacecr. Rocket. 2000, 37, 28-38. [CrossRef]

2. Bartels, R.E.; Chwalowski, P.; Massey, S.J.; Heeg, J.; Mineck, R.E. Computational aeroelastic analysis of the Ares I crew launch vehicle during ascent. J. Spacecr. Rocket. 2012, 49, 651-658. [CrossRef]

3. Yuan, W.; Wall, A.; Lee, R. Combined numerical and experimental simulations of unsteady ship airwakes. Comput. Fluids 2018, 172, 29-53. [CrossRef]

4. Dooley, G.; Martin, J.E.; Buchholz, J.H.; Carrica, P.M. Ship airwakes in waves and motions and effects on helicopter operation. Comput. Fluids 2020, 208, 104627. [CrossRef]

5. Zakeri, A.; Høeg, K.; Nadim, F. Submarine debris flow impact on pipelines-Part I: Experimental investigation. Coast. Eng. 2008, 55, 1209-1218. [CrossRef]

6. Akbari, H.; Pooyarad, A. Wave force on protected submarine pipelines over porous and impermeable beds using SPH numerical model. Appl. Ocean. Res. 2020, 98, 102118. [CrossRef]

7. Xiong, Q.; Lim, A.E.; Lim, Y.; Lam, Y.C.; Duan, H. Dynamic magnetic nanomixers for improved microarray assays by eliminating diffusion limitation. Adv. Healthc. Mater. 2019, 8, 1801022. [CrossRef] [PubMed] 
8. Lim, A.E.; Lim, C.Y.; Lam, Y.C.; Lim, Y.H. Effect of microchannel junction angle on two-phase liquid-gas Taylor flow. Chem. Eng. Sci. 2019, 202, 417-428. [CrossRef]

9. Choi, H.; Jeon, W.P.; Kim, J. Control of Flow over a Bluff Body. Annu. Rev. Fluid Mech. 2008, 40, 113-139. [CrossRef]

10. Yin, J.F.; You, Y.X.; Li, W.; Hu, T.Q. Numerical analysis for the characteristics of flow control around a circular cylinder with a turbulent boundary layer separation using the electromagnetic force. Acta Phys. Sin. 2014, 63, 044701. (In Chinese)

11. Jeon, S.; Choi, J.; Jeon, W.P.; Choi, H.; Park, J. Active control of flow over a sphere for drag reduction at a subcritical Reynolds number. J. Fluid Mech. 2004, 517, 113-129. [CrossRef]

12. Kimura, T.; Tsutahara, M. Fluid dynamic effects of grooves on circular cylinder surface. AIAA J. 1991, 29, 2062-2068. [CrossRef]

13. Kwon, K.; Choi, H. Control of laminar vortex shedding behind a circular cylinder using splitter plates. Phys. Fluids 1996, 8 , 479-486. [CrossRef]

14. Sun, X.; Suh, S.; Ye, Z.H.; Yu, B. Dynamics of a circular cylinder with an attached splitter plate in laminar flow: A transition from vortex-induced vibration to galloping. Phys. Fluids 2020, 32, 027104. [CrossRef]

15. Ghiasi, A.; Razavi, S.E.; Rouboa, A.; Mahian, O. Numerical study on flow over a confined oscillating cylinder with a splitter plate. Int. J. Numer. Methods Heat Fluid Flow 2019, 29, 1629-1646. [CrossRef]

16. An, X.Y.; Song, B.W.; Tian, W.L.; Ma, C.C. Numerical Research of Flow past a Circular Cylinder with Splitter Plate at a Subcritical Reynolds Number Region. J. Shanghai Jiaotong Univ. Sci. 2019, 24, 113-121. [CrossRef]

17. Anderson, E.A.; Szewczyk, A.A. Effects of a splitter plate on the near wake of a circular cylinder in 2 and 3-dimensional flow configurations. Exp. Fluids 1997, 23, 161-174. [CrossRef]

18. Apelt, C.J.; West, G.S.; Szewczyk, A.A. The effects of wake splitter plates on the flow past a circular cylinder in the range $10^{4}<\mathrm{R}<5$ $\times 10^{4}$. J. Fluid Mech. 1973, 61, 187-198. [CrossRef]

19. Apelt, C.J.; West, G.S. The effects of wake splitter plates on the flow past a circular cylinder in the range $10^{4}<\mathrm{R}<5 \times 10^{4}$. Part 2 . J. Fluid Mech. 1975, 71, 145-160. [CrossRef]

20. Roshko, A. On the Wake and Drag of Bluff Bodies. J. Aeronaut. Sci. 1955, 22, 124-132. [CrossRef]

21. Hwang, J.Y.; Yang, K.S.; Sun, S.H. Reduction of flow-induced forces on a circular cylinder using a detached splitter plate. Phys. Fluids 2003, 15, 2433-2436. [CrossRef]

22. Ozono, S. Flow control of vortex shedding by a short splitter plate asymmetrically arranged downstream of a cylinder. Phys. Fluids 1999, 11, 2928-2934. [CrossRef]

23. Bearman, P.W.; Zdravkovich, M.M. Flow around a circular cylinder near a plane boundary. J. Fluid Mech. 1978, 89, 33-47. [CrossRef]

24. Rathakrishnan, E. Effect of Splitter Plate on Bluff Body Drag. AIAA J. 1999, 37, 1125-1126. [CrossRef]

25. Bingham, C.; Morton, C.; Martinuzzi, E.J. Influence of control cylinder placement on vortex shedding from a circular cylinder. Exp. Fluids 2018, 59, 158. [CrossRef]

26. Chauhan, B.V.S.; Singh, V.P.; Sayyed, I.; Vedratnam, A. Flow pattern determination for circular staggered cylinders in cross flow using CFD. Civ. Eng. 2020, 5, 82-95.

27. Strykowski, P.J.; Sreenivasan, K.R. On the formation and suppression of vortex 'shedding' at low Reynolds numbers. J. Fluid Mech. 1990, 218, 71-107. [CrossRef]

28. Wang, G.X.; Wang, S.Y.; Ge, M.M.; Deng, X.G. High-order delay detached-eddy simulations of cylindrical separated vortex/vortex induced noise based on transition model and acoustic analogy. Acta Phys. Sin. 2018, 67, 194701.

29. Zhang, Z.; Wang, Z.; Gursul, I. Lift Enhancement of a Stationary Wing in a Wake. AIAA J. 2020, 58, 4613-4619. [CrossRef]

30. Gopalkrishnan, R.; Triantafyllou, M.S.; Triantafyllou, G.S.; Barrett, D.S. Active Vorticity Control in a Shear Flow Using a Flapping Foil. J. Fluid Mech. 1994, 274, 1-21. [CrossRef]

31. Streitlien, K.; Triantafyllou, G.S.; Triantafyllou, M.S. Efficient foil propulsion through vortex control. AIAA J. 1996, 34, 2315-2319. [CrossRef]

32. Chao, L.M.; Zhang, D.; Cao, Y.H.; Pan, G. Numerical studies on the interaction between two parallel D-cylinder and oscillated foil. Mod. Phys. Lett. B 2018, 32, 1850034. [CrossRef]

33. Xiao, Q.; Sun, K.; Liu, H.; Hu, J.X. Computational study on near wake interaction between undulation body and a D-section cylinder. Ocean. Eng. 2011, 38, 673-683. [CrossRef]

34. Spalart, P.R.; Allmaras, S.R. One-equation turbulence model for aerodynamic flows. Rech. Aerosp. 1994, 1, 5-21.

35. Roe, P.; Pike, J. Efficient construction and utilisation of approximate Riemann solutions. Comput. Methods Appl. Sci. Eng. 1984, 43, 499-518.

36. Yoon, S.; Jameson, A. Lower-upper symmetric-gauss-seidel method for the euler and navier-stokes equations. AIAA J. 1988, 26, 1025-1026. [CrossRef]

37. Zhang, L.P.; Wang, Z.J. A block LU-SGS implicit dual time-stepping algorithm for hybrid dynamic meshes. Comput. Fluids 2004, 33, 891-916. [CrossRef]

38. Chang, X.H.; Zhang, L.P.; He, X. Numerical study of the thunniform mode of fish swimming with different Reynolds number and caudal fin shape. Comput. Fluids 2021, 68, 54-70. [CrossRef]

39. Chang, X.H.; Ma, R.; Zhang, L.P. Parallel implicit hole-cutting method for unstructured overset grid. Acta Aeronaut. Astronaut. Sin. 2018, 39, 121780. (In Chinese) 
40. Landon, R.H. NACA0012 oscillation and transient pitching. In Compendium of Unsteady Aerodynamic Measurements: Advisory Report 702; AGARD: Hampton, VA, USA, 1982.

41. Duan, X.P. Dynamic Hybrid Grid Generation Method for Complex Geomtries and Numerical Method for Unsteady Compressible Flows; Aerodynamics Research and Development Center: Mianyang, China, 2008; pp. 69-72. (In Chinese) 